\title{
Arsenic stabilization in soil using two kinds of steel slags having different chemical characteristics as soil stabilizer
}

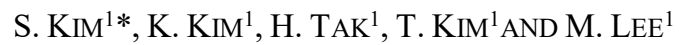 \\ ${ }^{1}$ Dept. of Earth Environmental Sciences, Pukyong National \\ University, South Korea \\ (*correspondence: kkseonhee@gmail.com)
}

The arsenic (As) stabilization mechanisms according to the chemical properties of the steel slag were studied by laboratory experiments. Steel slags used in experiments as the soil stabilizer were classified into Ca-based steel slag and Fe-based steel slag according to their chemical characteristics. Ca-based steel slag (CS) was steel slag with high $\mathrm{pH}$ value and high content of calcium without aging treatments. Fe-based steel slag (FS) was oxidized by the several years aging treatment and had abundant $\mathrm{Fe}, \mathrm{Mn}$, and $\mathrm{Al}$ rather than $\mathrm{Ca}$. The As contaminated soil used in the experiment was collected from the surface of the tailing dam in Korea. The initial As concentration in soil was $2,225 \mathrm{mg} / \mathrm{kg}$, about 11 times higher than the Korean Soil Pollution Warning Limit (KSPWL: 200 $\mathrm{mg} / \mathrm{kg}$ ). To investigate the As stabilization mechanism of two different steel slags in soil, each steel slag was reacted with artificially As contaminated solution and the surface of steel slag was analyzed by FE-SEM/EDS after the reaction. In the case of CS, the Ca-As precipitates were broadly found out onto the surface of CS particles. However, for FS, As was adsorbed locally onto the surface of iron oxides contained in FS particles. These results suggested that different stabilization mechanisms may be applied for As contaminated soil if the CS and the FS are utilized as soil stabilizers. To investigate the change in the As-bonding from of soil generated during various stabilization processes, the sequential extraction procedure (SEP) were conducted for only soil (FS-soil: soil stabilized with FS and $\mathrm{MnO}_{2}$; CS-soil: soil stabilized with CS). The stabilized soil samples were sequentially extracted using the Wenzel's SEP method. In case of CS-soil, the portion (\%) of As bound in the $1^{\text {st }}$ and $2^{\text {nd }}$ stages by the calcium carbonates (by coprecipitation) and calcium arsenate formation increased up to $6.0 \%$ by the stabilization process of CS. In case of FS-soil, by the adsorption on Fe-oxide and Mn-oxide, the As portion(\%) at the $1^{\text {st }}$ and $2^{\text {nd }}$ stages decreased by $1.4 \%$ than soil. The main As stabilization mechanism of CS in soil was considered as the precipitation of Ca-bearing minerals (including the coprecipitation of $\mathrm{CaCO}_{3}$ ). The As adsoption of Fe-Mn oxide minerals, on the other hand, was regarded as the main As stabilization mechanism for FS. 